\title{
Svante Arrhenius, cosmical physicist and auroral theorist
}

\author{
H. Kragh \\ Centre for Science Studies, Aarhus University, Building 1520, 8000 Aarhus, Denmark
}

Correspondence to: H. Kragh (helge.kragh@ivs.au.dk)

Received: 30 April 2013 - Revised: 16 June 2013 - Accepted: 25 June 2013 - Published: 4 July 2013

\begin{abstract}
Many scientists in the fin de siècle era saw a need to coordinate and unify the increasing amount of data relating the physical conditions of the Earth and the Sun; or more generally to establish a synthetic perspective that covered the earth sciences in relation to the new astrophysical sciences. Promoted under the label "cosmical physics", the unifying solar-terrestrial perspective was in vogue for a decade or two. Perhaps more than any other scientist in the period, the versatile Swedish chemist and physicist Svante Arrhenius represented the aims of cosmical physics. A central problem in the new and ambitious research programme was to understand the origin and nature of the aurora, and to relate it to other celestial phenomena such as the solar corona and the tails of comets. In 1900 Arrhenius proposed a unified explanation of these and other phenomena based on the Sun's radiation pressure. The theory was widely discussed, praised as well as criticized. Arrhenius was not only a key scientist in the short-lived tradition of cosmical physics, but also influential as a popular writer and powerful member of the Nobel Committee for Physics. His work illustrates an approach to the earth and space sciences characteristic of the fin de siècle period.
\end{abstract}

\section{Introduction}

The Swedish chemist and physicist Svante August Arrhenius was born on 19 February 1859 at Vik, near Uppsala, and he died on 2 October 1927 in Stockholm. During the first decade of the 20th century, he was at the height of his career. A Nobel laureate of 1903, Arrhenius was not only a prominent scientist but also known to the general public for his popular books and articles (Amelin, 1993). He was one of the European luminaries invited to the 1904 Congress of Arts and Science in St. Louis, where he gave a much publicized lecture in the section of "cosmical physics" on the relation of meteorology to other branches of science (Fig. 1). A correspondent of the Popular Science Monthly was impressed:

The section of cosmical physics was ... remarkable for the ideals of synthesis and the spirit of cooperation which pervaded it. In an address as bold as it was original Arrhenius proposed a theory of the possible connection between phenomena the most diverse and separated by exceedingly great distances, thus, e.g., raising meteorology to the dignity of a cosmic science (Davis, 1904, 25).
In this paper I present Arrhenius as a cosmical physicist rather than a physical chemist. The concept of cosmical physics has no modern equivalent but needs to be understood in the historical context of fin de siècle science. After having introduced the concept, I describe Arrhenius' career up to the beginning of the 20th century, at a time when he was deeply immersed in cosmical physics. I pay particular attention to the theory of the aurora and the tails of comets that he proposed in 1900 and which served as a blueprint for his later and more speculative work of a cosmological nature. Arrhenius' science and career illustrate some of the essential features of cosmical physics and thereby open up for insight into a perspective on the earth and space sciences that belonged exclusively to the period around the turn of the century.

\section{Origins of cosmical physics}

In the fin de siècle period from about 1890 to 1915 , many astronomers, meteorologists and geophysicists engaged in interdisciplinary research projects with the aim of integrating terrestrial, solar and astrophysical sciences. Under the umbrella label "cosmical physics" they investigated, for example, geomagnetic storms, the aurora, meteorites, atmospheric 
electricity and comets' tails (Kragh, 2013). The 1911 edition of Encyclopaedia Britannica included an entry on the new branch of science, defining it as follows (http://www. 1911encyclopedia.org/Cosmic):

"Cosmical physics" is a term broadly applied to the totality of those branches of science which treat of cosmical phenomena and their explanation by the laws of physics. It includes terrestrial magnetism, the tides, meteorology as related to cosmical causes, the aurora, meteoric phenomena, and the physical constitution of the heavenly bodies generally. It differs from astrophysics only in dealing principally with phenomena in their wider aspects, and as the products of physical causes, while astrophysics is more concerned with minute details of observation.

Cosmical physics with more or less this meaning appeared first in Germany, where it was inspired by Alexander von Humboldt's holistic view of the universe as unfolded in his hugely popular Kosmos, the first volume of which was published in 1848. According to the German author Otto Ule (1851), kosmische Physik was the description of nature in the spirit of Humboldt, that is, terrestrial and astronomical phenomena bound together by the laws of physics. Five years later the physicist Johann Müller, professor at the University of Freiburg in Breisgau, published the first textbook in cosmical physics, a field that principally covered astronomy, physical meteorology, terrestrial magnetism and the influence of the Sun on the Earth and its atmosphere (Müller, 1856). Lehrbuch der kosmischen Physik became a success, appearing in several editions. As late as 1894, 19 years after Müller had passed away, a fifth revised edition was published under the editorship of the Kiel astronomer Carl Peters (Müller and Peters, 1894; Lockyer, 1894).

In the late 1860 s a somewhat different version of cosmical physics turned up in England, where it was promoted by Balfour Stewart, Professor of Natural Philosophy at Owens College, Manchester. An advocate of what he called "cosmical meteorology", Stewart argued that there was a need to strengthen physical or cosmical meteorology and generally to bring the earth sciences into closer contact to astronomy (Gooday, 2007). In an address of 1870 on cosmical physics, he said that recent advances in the field "tend to indicate the probable union of the various branches of observational inquiry into one great cosmical research, and point to the wisdom of a very close union between the workers in the cognate fields of meteorology, terrestrial magnetism, and celestial physics" (Stewart, 1870, 500).

To make a long story short, in the years from about 1890 to 1910, cosmical physics flourished in several European countries, although it never developed into a proper scientific discipline. Only in the Austro-Hungarian Empire did the field become institutionalized with university chairs and institutions (Crawford, 1996, 132-134; Kragh, 2013). Apart from

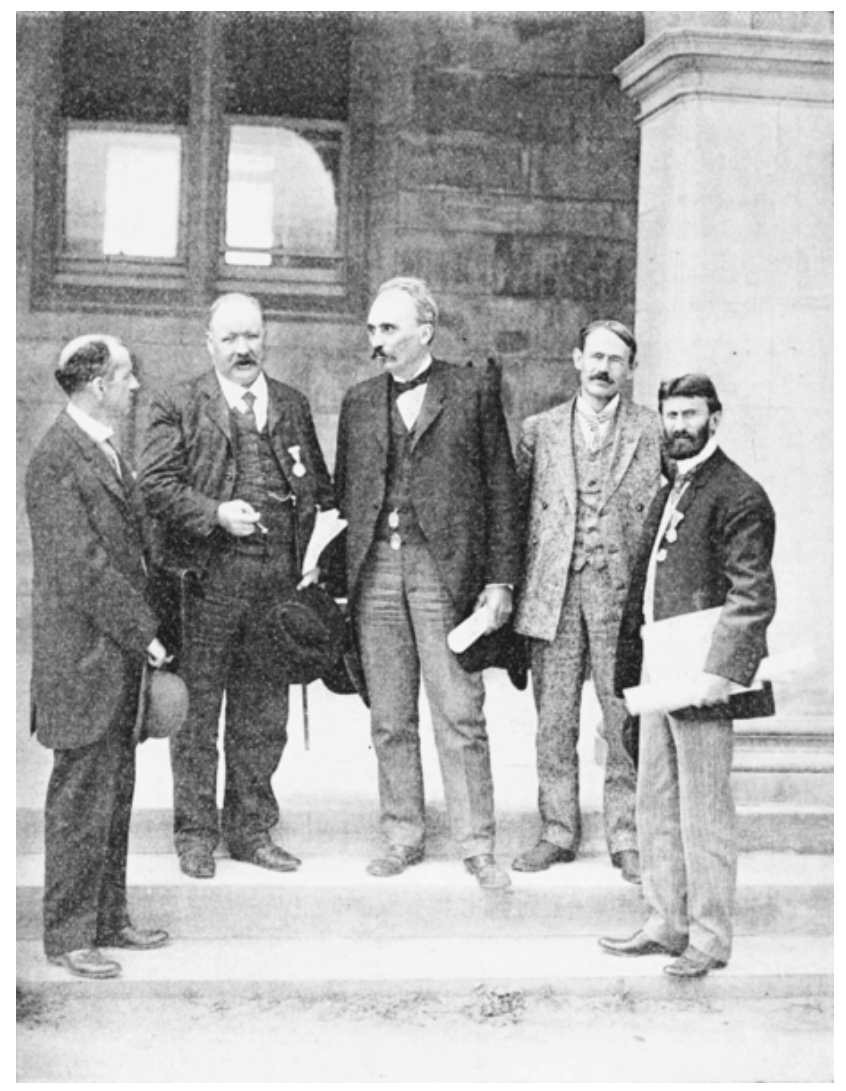

Figure 1. Arrhenius at the 1904 St. Louis Congress. To his left, the American meteorologist Abbott Rotch and, to the far right, the American geophysicist Louis Bauer. Source: Popular Science Monthly Vol. 66 (1904).

Vienna and Innsbruck, other centres of cosmical physics of a more informal character were located in Manchester, Stockholm and Oslo. However, in spite of the professed aim of cosmical physics, it remained a heterogeneous collection of subdisciplines rather than a unifying perspective on terrestrial and astronomical sciences. The Viennese meteorologist and geophysicist Wilhelm Trabert realized that cosmical physics was in danger of becoming just a conglomerate of already existing disciplines and subdisciplines. In a textbook from 1911, he described cosmical physics as "a series of disciplines, a loose juxtaposition of astrophysics, the physics of the solid and fluid parts of the Earth, and the physics of the atmosphere, that is, a physics that links together what in the universe is locally unified" (Trabert, 1911, iv).

Probably more than any other scientist, Svante Arrhenius represented the spirit and breadth of cosmical physics. A look at some of the activities of the versatile Swedish chemist and physicist will give an impression of the nature and diversity of cosmical physics, or what The Times on 27 December 1904 called "a department of science which ... has justified its existence by growing rapidly and healthily." 


\section{From physical chemistry to solar-terrestrial sciences}

After undergraduate studies at the University of Uppsala, in 1881 Arrhenius went to Stockholm College (Högskola) to prepare for his doctoral dissertation in Uppsala (Riesenfeld, 1931; Crawford, 1996). The college, a private institution for scientific studies at university level, was only granted the right to award doctorates in 1904. In 1960 it obtained formal status as a university, now renamed Stockholm University. While in Stockholm, Arrhenius investigated the electrical conductivity of electrolytes, which was an important part of his dissertation of 1884. In this work he introduced the ionic theory of dissociation in solvents, which turned out to be of such importance that it earned him a Nobel Prize in chemistry in 1903. However, the dissertation was initially received with much scepticism and graded poorly by the Swedish professors in the examination committee. The essence of Arrhenius' new theory was that electrolytes such as salts and acids underwent incomplete dissociation when in an aqueous solution, and that even in the absence of an external electrical field. While neither water nor the pure electrolyte was ionized, the combination of the two produced a partial decomposition into ions. Although the theory was initially dismissed in Sweden, many chemists elsewhere in Europe found it to be a promising advance. Arrhenius' ionic theory soon became a cornerstone of the new and highly successful discipline known as physical chemistry, but it also created a good deal of controversy in chemistry circles (Coffey, 2008, 3-37; Fig. 2).

In 1886 Arrhenius received a travel grant from the Royal Swedish Academy of Sciences, which he used for extensive studies abroad. He first worked with Wilhelm Ostwald in Riga, and then went on to Friedrich Kohlrausch in Würzburg and to Ludwig Boltzmann in Graz; he ended his Wanderjahre with a stay at Jacobus van't Hoff's laboratory in Amsterdam. In 1891 he was appointed lecturer at Stockholm College, and promoted four years later to professor of physics. In 1905 he became the first director of the Nobel Institute for Physical Chemistry under the Royal Swedish Academy, a position he held until shortly before his death in 1927, at the age of 67 .

Whereas in his younger days Arrhenius mostly published on physical chemistry and electrochemistry, from about the time he returned to Stockholm he increasingly focused on areas within the broad category of cosmical physics. The interest was not new to him; as early as 1883 he had published a study on the flashes of ball lightning in the proceedings of the Royal Swedish Academy (Arrhenius, 1883). Five years later, when studying in Graz, he investigated the influence of ultraviolet light on the electrical conductivity of the atmosphere (Arrhenius, 1888). Atmospheric electricity was at the time a specialty of the Viennese physicist Franz Exner, according to whom the surface of the Earth was negatively charged and the cause of the atmosphere's electrical field. Arrhenius' work, published in the Austrian-German Meteo-

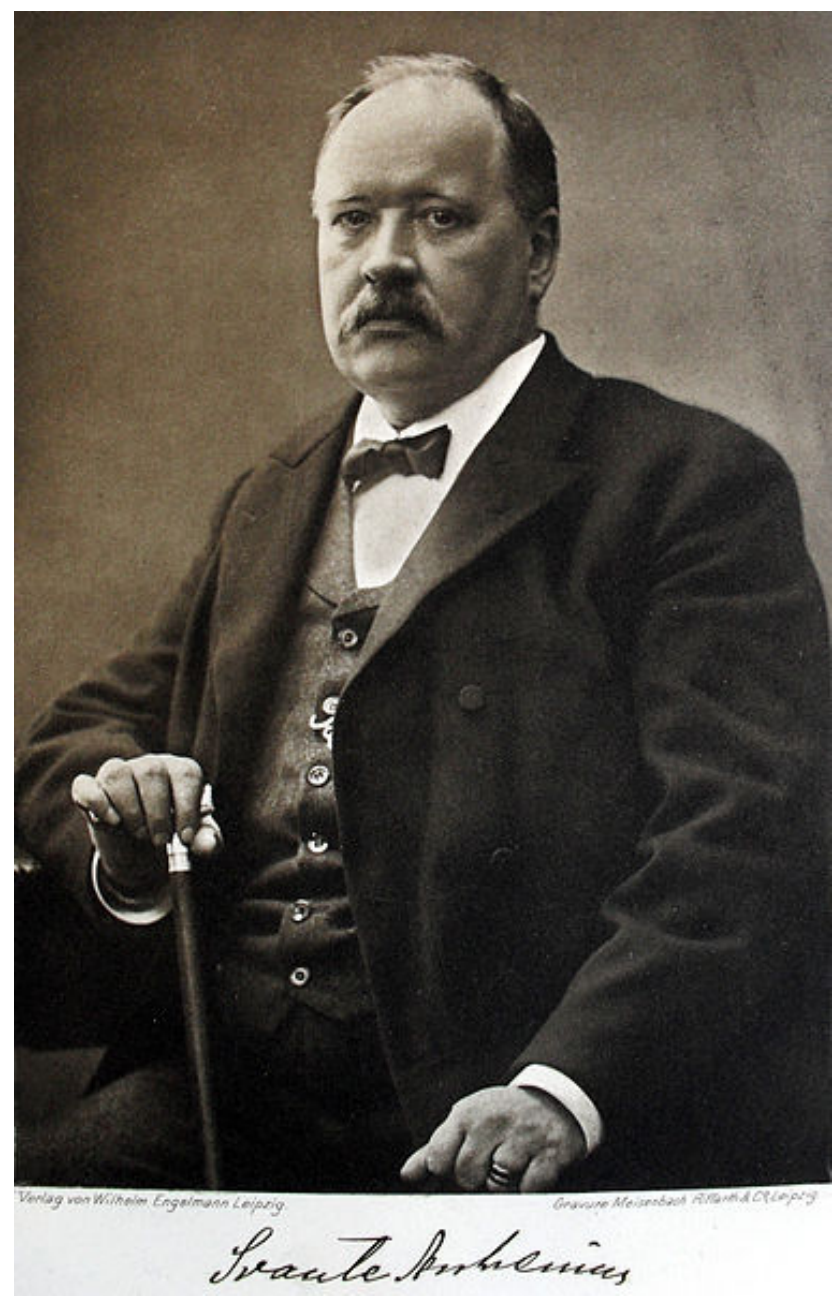

Figure 2. Arrhenius celebrated as a co-founder of physical chemistry. Source: Zeitschrift für physikalische Chemie Vol. 69 (1909).

rologische Zeitschrift edited by Julius Hann in Vienna, was essentially an improvement of Exner's theory by taking into regard the action of the Sun's ultraviolet light. In an earlier paper, reporting laboratory experiments on how ultraviolet light influences the conductivity of air, he used for the first time the term "cosmical physics" for studies of the kind conducted by himself and Exner (Arrhenius, 1887).

These early contributions to cosmical physics were the beginning of a long series of works that covered a broad spectrum of terrestrial and cosmical sciences, including meteorology, volcanology, auroral studies, climatology, chemical processes in the crust of the Earth, and the formation of the solar system - not to mention subjects of an astronomical, astrophysical and cosmological nature. Altogether, Arrhenius published more articles and books on subjects within the category of cosmical physics than on any other branch of science (Arrhenius, 1959; Arrhenius et al., 2008, 7). Of the 190 publications listed in his bibliography, 57 can be classified as belonging to cosmical physics. 
The same year that Arrhenius started in his position as physics lecturer at Stockholm College, he took the initiative to establish a Physics Society (Fysiska Sällskapet) with the aim of offering lectures and promoting discussions related to physics in a broad sense. What was defined as physics within the society included neighbouring fields such as meteorology, geophysics, astrophysics, oceanography and physical chemistry (Crawford, 1996, 120-122, 237-240). The Physics Society soon grew in importance and came to serve as an informal centre of cosmical physics in Sweden. During the academic year 1899-1900, Arrhenius gave a series of lectures on cosmical physics which became the foundation of his 1903 textbook on the subject, the Lehrbuch der kosmischen Physik (Sect. 6).

Among the members of the Physics Society, some were more active and prominent than others. Apart from Arrhenius, they comprised the geochemist Arvid Högbom and the meteorologist Nils Ekholm, both of whom belonged to Arrhenius' inner circle. The same was the case with the Norwegian physicist and meteorologist Vilhelm Bjerknes, who in 1895 had been appointed professor of applied mechanics and mathematical physics at Stockholm College. He stayed in Stockholm until 1907, afterwards returning to Oslo. Yet another important member of the Physics Society was Otto Pettersson, professor of chemistry at the college and an early supporter of Arrhenius' dissociation hypothesis. Although his chair was in chemistry, today he is best known as a pioneer of physical oceanography. Pettersson served as Rector of Stockholm College 1893-1896, to be followed by Arrhenius.

Many of the papers that Arrhenius published in the 1890s were of a physical-meteorological nature, in so far that they dealt with changes in the atmosphere caused by cosmic and other sources. The best known of them is undoubtedly his 1896 model of how variations in the content of carbon dioxide in the atmosphere cause climatic changes including the ice ages. Today known as a classic of the greenhouse effect (a name Arrhenius did not use), this work arose from discussions in the Physics Society and rested on Högbom's ideas of the carbon cycle in nature (Arrhenius, 1896; Crawford, 1997). Arrhenius supposed volcanic eruptions to be the main source of atmospheric carbon dioxide, and in 1901 he investigated the mechanism of volcanic activity on the basis of physical chemistry (Arrhenius, 1901a). However, his volcanic theory soon proved untenable.

Other of Arrhenius' papers from the same period were more clearly in the tradition of cosmical physics, as they related terrestrial phenomena to solar, lunar and other extraterrestrial causes. Assuming that the Moon was negatively electrified, he and Ekholm studied the influence of our satellite on the electric state of the Earth's atmosphere and also on thunderstorms and the aurora borealis. The kind of study pursued by Arrhenius and Ekholm was taken up also by Pettersson, who in a paper of 1914 investigated the relationship between sunspots and climatic changes, and between lunar periods and solar activity (Pettersson, 1914).

Given the volume and breadth of Arrhenius' engagement in cosmical physics, it is not possible to cover it comprehensively. I shall focus on what is arguably his most important paper of the period, a work in which he suggested an explanation of the tails of comets and the origin of aurorae on the basis of the Sun's radiation pressure.

\section{Theories of the aurora}

At the time when Arrhenius turned to the origin of the aurora, the subject had long attracted interest among physicists and meteorologists. A possible connection between auroral displays and electrical discharges had been suggested as early as in the mid-18th century, and in the latter part of the following century the idea was widely accepted (Harvey, 1957, 255-263). Based on model experiments with discharge tubes, the young Finnish physicist Karl Selim Lemström concluded in 1876 that the aurora was an electrical current flowing from the higher strata of the atmosphere down to the Earth (Hedenus, 2007, 127-132; Holmberg, 1996). Versions of this general idea, namely, that the aurora was an electrical discharge phenomenon similar in nature to lightning, were propounded also by Erik Edlund in Sweden and Auguste de la Rive in Switzerland (Brekke and Egeland, 1983, 78-81). However, what the discharges consisted of, more precisely, was unknown at the time and only gradually clarified as laboratory studies of discharges in dilute gases progressed.

In 1876 the German physicist Eugen Goldstein, at the time a 25-year-old research student under Hermann von Helmholtz in Berlin, coined the name "cathode rays" for the negatively charged rays that his compatriot Johann Wilhelm Hittorf had first identified in 1869 . In a paper of 1881 he proposed that the Sun emits electrical rays analogous to cathode rays into space. Experiments show, he said, "that no limit for the extension of what we call cathode rays exists and it may be conceivable that the Sun besides light also sends out into space electrical rays" (Goldstein, 1881, 266). He thought that the hypothesis might explain the tails of comets in a way that was superior to other cometary theories of an electrical kind, such as proposed by Osborne Reynolds in Manchester and Karl Friedrich Zöllner in Leipzig (Heidarzadeh, 2008, 223228). Moreover, it might explain certain unspecified "terrestrial phenomena of an electrical and magnetic nature." Although he did not mention the aurora in his 1881 paper, he did so in an unpublished memoir six years later (Hedenus, 2007, 217-222). In his memoir of 1870, Reynolds suggested that cometary tails, aurorae and the solar corona were all due to the same electrical cause, but without assuming "the sun to be a reservoir of electricity, which is continually pouring into space" (Reynolds, 1900, 13). 
The Danish physicist Adam Paulsen, since 1884 director of the Meteorological Institute in Copenhagen, may have been the first to propose cathode rays as the immediate cause of aurorae. Reporting on a series of observations made in Greenland, in 1894 he concluded that "the rays producing the aurora and the cathode rays are electrical phenomena of the same nature" (Paulsen, 1894; Jørgensen and Rasmussen, 2006). He argued that the auroral light was caused by fluorescence in the air due to absorption of cathode rays in the upper regions of the atmosphere, these regions being covered by a layer of negative electricity. The hypothetical negative layer was thus the immediate source of the cathode rays. Although he did not propose the Sun as the generator of cathode rays, he admitted that ultimately the energy of the aurora was of solar origin. Paulsen was considered an authority on auroral physics, and at the turn of the century his theory, or something like it, enjoyed wide acceptance.

The pioneering theory of the Norwegian physicist Kristian Birkeland combined, in a sense, elements of Goldstein's ideas and those proposed by Paulsen. Based on experiments with the magnetic action on cathode rays, in 1896 he suggested the existence of solar cathode rays that "come from cosmic space and are in particular absorbed by the Earth's magnetic pole, and that in some way or other they must be attributed the Sun" (Birkeland, 1896, 512). In a series of subsequent papers, he explained that sunspots were the main source of the cosmic cathode rays, if not the only source. The rays from the Sun would be deflected and accelerated in the magnetic field of the Earth and, as they reached the upper strata of the atmosphere, they would be slowed down, in the process exciting and ionizing the atoms. As a result, the atoms would emit light of the colours characteristic of the aurora. Birkeland soon provided support for his cathode ray theory by means of a spectacular series of experiments with a magnetized "terrella" made of steel placed in a large vacuum chamber and exposed to cathode rays (Egeland and Burke, 2010).

\section{Radiation pressure, aurorae and comets' tails}

In 1900 Arrhenius came up with yet another explanation of the aurora, which he also used to account for the tails of comets, the solar corona and several other celestial phenomena. Although it had features in common with earlier electrical theories, it differed from them by being innovatively based on the Sun's radiation pressure. The existence of a feeble radiation or light pressure had been discussed for nearly two centuries, and in the 1870s the hypothesis attracted increased attention. In 1873 Maxwell predicted from his electromagnetic field theory that light waves exert a pressure, which he, in the case of strong sunlight, calculated to $8.82 \times 10^{-8} \mathrm{lb}$ per square foot or $6.64 \times 10^{-7} \mathrm{~g} \mathrm{~cm}^{-2}$ (Maxwell, 1873 , Vol. 2, 441). In modern units, the value is $4.2 \times 10^{-6} \mathrm{~Pa}$. A few years later the Italian physicist Adolfo Bartoli ar- gued independently for a radiation pressure, which Boltzmann confirmed and amplified in a paper of 1884 (Carazza and Kragh, 1989).

As Arrhenius was aware, in 1892 the Russian physicist Peter Lebedev had proposed the pressure of sunlight as a possible cause of why comets' tails point away from the Sun. At the 1900 International Congress of Physics in Paris, Lebedev (1900) presented further evidence for what he called the "Maxwell-Bartoli pressure", suggesting that it might explain the motion of comets and their formation from swarms of tiny meteorites. He did not refer to the aurora. Only the following year did he publish the final results of his experiments, concluding that he had now proved the existence of a light pressure in accordance with Maxwell's prediction (Lebedev, 1901). His 1901 paper is generally acknowledged as the discovery of light or radiation pressure.

Even in the absence of solid experimental proof, Arrhenius had no doubt that the radiation pressure was real. Referring to Maxwell's predicted value at the Earth, he (1900, 83 ) found the much stronger pressure of $2.75 \times 10^{-3} \mathrm{~g} \mathrm{~cm}^{-2}$ at the surface of the Sun. His basic hypothesis was that the Sun ejects streams of very fine drops of matter or cosmic dust particles and that some of these particles are blown out into space by the radiation pressure. For a spherical drop of diameter $1.5 \times 10^{-4} \mathrm{~cm}$ and density $1 \mathrm{~g} \mathrm{~cm}^{-3}$, he calculated that the radiation pressure at the Sun's surface would balance the gravitational attraction. Larger and heavier particles would also be emitted from the Sun's surface, but they would fall back again as a result of gravity predominating over the light pressure. Arrhenius further argued that the particles ejected by the Sun must be electrically charged, which he found confirmed by recent experiments of Charles T. R. Wilson at the Cavendish Laboratory and also by the violent electrical disturbances known to accompany volcanic eruptions on the Earth (Arrhenius, 1900, 97). While both positive and negative particles were emitted, only the negatively charged would act as condensation nuclei and leave the Sun. In addition to the negative dust particles carried away by the radiation pressure, he suggested that also cathode rays and X-rays were emitted from the Sun's atmosphere.

According to Arrhenius, the mentioned mechanism was able to account for both the formation of comets' tails and the aurora borealis, including the cycle of $11 \mathrm{yr}$ corresponding to the periodicity of sunspots. As far as the aurora was concerned, when the electrified dust particles sailing on the radiation pressure reached the Earth's upper atmosphere, they would be discharged and in the process cause the atmospheric atoms to emit the colours characteristic of aurorae. Cathode rays played a role in Arrhenius' theory, but an indirect one only. As he explained in a later paper (1903a, 496):

As these drops are driven away by the pressure of radiation they charge with negative electricity the atmospheres of the celestial bodies, e.g., the earth, ... till the charge is so great that discharges 
occur, and cathode rays are formed, which carry the charge back to the universe.

That is, the cathode rays involved in the process were produced in the atmosphere and did not originate from the Sun. He found his own view of the formation of the aurora to be superior to that held by "some authors", namely, "that the negative electricity was carried away from the sun by means of cathode rays" (p. 499). Although he clearly had Birkeland in mind, he refrained from mentioning his name. This was no casual oversight, for in his many papers and books he systematically avoided referring to the Norwegian specialist in auroral research. It was not Arrhenius' style to cite scientists he felt might be his rivals.

The new theory of the cosmic and terrestrial effects of solar radiation pressure was much discussed in the first decade of the 20th century. For example, in a Royal Institution lecture of 1901, J. J. Thomson discussed the role of the new electrons - or what he called "corpuscles" - in cosmic and terrestrial physics. He described at some length the hypothesis that "the sun gives out corpuscles which travel out through interplanetary space [and] ... strike the upper regions of the earth's atmosphere", giving the audience the false impression that this was the view of Arrhenius (Thomson, 1901, 149; see also Thomson, 1903, 165). He was favourably impressed by the "very satisfactory" theory of the aurora proposed by the Swedish scientist.

Whereas Thomson did not mention the radiation pressure - the essential element in Arrhenius' theory - this was what caught the attention of the brilliant German astronomer Karl Schwarzschild, who the same year examined the theory critically and in mathematical detail (Schwarzschild, 1992; Arrhenius, 1908, 97-99). By taking into consideration the diffraction effects of light, he showed that for very small particles Arrhenius' theory was in need of revision. According to Schwarzschild's calculations, particles of molecular size would not be repelled by the light pressure, but fall back into the Sun.

John Cox, a physics professor at McGill University, Montreal, offered a detailed and sympathetic review of the theory in Popular Science Monthly. He praised it for being based on a single physical principle, the radiation pressure of electromagnetic waves, and yet explaining an astonishingly wide range of phenomena. Arrhenius' theory, he said (Cox, 1902, 278),

... gives a rational explanation of the astounding behavior of comets' tails; accounts for the "hairy" structure of the corona; shows us how the prominences can float where the existence of a supporting atmosphere is inadmissible; what is the origin of the zodiacal light and the Gegenschein; ... of the aurora, and why it is subject to such complicated periodical variations; why meteorites are porous and limited in size; how the nebulae shine in the absolute cold of inter-stellar space, and yet hang together.

Not all scientists received the theory with such enthusiasm. Some specialists in auroral research objected to Arrhenius' claim of having provided a theory that gave a nearly full explanation of auroral phenomena. According to Birkeland (1901), this was not the case at all, as the energy of the pressure-driven dust particles was not even sufficient to produce the light of the aurora. Also Paulsen objected to Arrhenius' theory, which he found to be unable to account for aurorae at middle and low latitudes and also to suffer from other weaknesses (Paulsen, 1906; Stauning, 2011). Finally, the Edinburgh astronomer Jacob Halm (1902) criticized Arrhenius' theory for resting on "arbitrary and unwarranted assumptions" regarding the mechanism of radiation pressure. Contrary to Birkeland and Paulsen, Halm focused on the theory in relation to the tails of comets rather than as a theory of the aurora.

\section{A new textbook in cosmical physics}

The breadth and ambitions of Arrhenius' research interests are nowhere better represented than in the Lehrbuch der kosmischen Physik that he published in 1903 after two years of hard work (Arrhenius, 1903b; Crawford, 1996, 162-164). The massive treatise of more than 1000 pages was organized in two volumes, of which the second was largely devoted to atmospheric physics and associated issues. Full of data, tables and historical information, its approach was basically descriptive rather than theoretical. Without offering a definition of the book's subject - and without referring to Müller's earlier and similarly titled textbook - Arrhenius described cosmical physics as an "extraordinarily versatile science" that had recently made remarkable progress. He pointed out in the preface that "I have tried to avoid questions that relate purely to astronomy, hydrography, geology and meteorology; and, as far as possible, I have dealt only with such problems that have intimate connections to physics and chemistry."

What, then, were the subjects covered by this extraordinarily versatile science? After a solid introduction to spectroscopy and astrophysics, Arrhenius dealt in the first volume with the main branches of geophysics, including topics such as volcanology, oceanography, hydrography and the age of the Earth. In the subsequent chapters on the physics of the atmosphere he dealt with, for example, meteorological optics, atmospheric electricity, the aurora and geomagnetism. His extensive chapter on the aurora was mostly of a descriptive nature, but of course he also included his own theory based on the Sun's radiation pressure. Although he mentioned hundreds of authors, he avoided references to the literature altogether. This may appear unsatisfactory, but at the time it was normal practice for encyclopaedic books of its kind. For example, Trabert's later textbook in cosmical physics followed the same practice. 
Arrhenius' conception of cosmical physics was extremely wide, covering not only the Earth and the Sun but also the universe in its totality. As early as 1900, in his paper on the aurora and cometary tails, he suggested that the mechanism of light pressure might be useful in understanding the nature and formation of the enigmatic nebulae. The following year he extended the framework of his theory to a truly cosmological scale, advocating a stellar universe infinite in both space and time (Arrhenius, 1901b; Kragh, 2013). His Lehrbuch included a chapter on "cosmogony" in which he critically discussed questions of a cosmological nature, such as the assumption of a continual increase of entropy in the universe. He would soon expand on this and related topics, which he presented as a qualitative cosmological theory in his bestselling Worlds in the Making, a translation of a Swedish book from 1907 (Arrhenius, 1908). Arrhenius' cosmological speculations make up a fascinating study, but they are not part of the present essay.

The new and impressive Lehrbuch der kosmischen Physik did not become the success that Arrhenius might have envisaged. Perhaps the reason was, as suggested by James Fleming $(1998,80)$, that it was "a textbook for a discipline that did not exist." Given that cosmical physics was not established as a proper scientific discipline, and that there were very few courses in the subject, the use of Arrhenius' book must have been limited. It was translated into Russian in 1905, but did not appear in either a French or an English edition. One of the problems with the book, and with the cosmical physics project generally, was its breadth: specialists in one field of research, for example meteorology or solar physics, would find the book superficial in that particular field, whereas they would pay little attention to the other parts of the book and fail to appreciate its synthetic aim.

Arrhenius' Lehrbuch received disappointingly few reviews, one of the few appearing in Meteorologische Zeitschrift (Vol. 20, 1903, 527-528). The reviewer, German climatologist Gustav Hellmann, expressed reservation with regard to Arrhenius' decision to leave out questions of a purely meteorological nature. On the other hand, Hellmann thought the book lived up to the higher aim of cosmical physics, which he formulated as "the integration into one closed system of all applications of the laws of physics to problems of the heavens and the Earth." The only positive evaluation that I know of appeared in New York Times of 6 July 1907, where the science writer Carl Snyder praised "the text-book of cosmical physics from the pen of Arrhenius" as an "original and stimulative work [in which] we see for the first time in its entirety the cycle of the cosmic machine."

\section{A note on Nobel Prizes}

As well known, there is no Nobel Prize for either astronomy or the earth sciences. The absence of earth and space scientists among the physics laureates in the first decades of the Nobel institution was a matter of negotiation rather than predetermined by the rules of the institution. In the early years of the Nobel system, it was agreed that whereas astrophysics was eligible, pure astronomy was not (Friedmann, 2001; Crawford, 1984). Also meteorology and allied sciences, including cosmical physics, were initially seen as unproblematic in the context of Nobel physics. For example, in 1906, 1911 and again in 1913 the leading Austrian meteorologist Julius Hann was nominated for the Nobel Prize in physics, and in none of the cases were the nominations disallowed with the argument that his work in meteorology did not belong to physics.

Hugo Hildebrandsson, a Stockholm professor of meteorology and member of the Nobel Committee for Physics, was in favour of including cosmical physics among the fields eligible for a physics prize. Another member of the committee, the physicist Vilhelm Carlheim-Gyllensköld, likewise sought to promote research in geomagnetism and auroral physics. In the years 1915, 1916 and 1917, he nominated Birkeland and his compatriot Carl Størmer for their contributions to unravelling the secrets of the aurora. By proposing the two Norwegians, he hoped to establish a department of cosmical physics at the Nobel Institute in Stockholm. Although CarlheimGyllensköld's proposal received some backing from other members of the Nobel Committee, it was sabotaged by Arrhenius, who had been a member of the Nobel Committee for Physics since its beginning in 1900. Arrhenius' reason was not dislike of cosmical physics, of course, but part of his plan to keep astronomy and astrophysics out of the Nobel physics institution.

When Arrhenius resigned his physics professorship at Stockholm College in 1905 to become head of the new Nobel Institute for Physical Chemistry, the influential Swedish mathematician Gösta Mittag-Leffler wanted Birkeland to replace him. Mittag-Leffler disliked Arrhenius, whom he considered a good chemist turned into a poor physicist. Moreover, he was involved in a long-time feud with Arrhenius over the physics Nobel Prize that centred on the campaign that Mittag-Leffler had orchestrated to award Henri Poincaré the prize (Stubhaug, 2010; Friedman, 2001, 49-52). The campaign failed, primarily because of Arrhenius' determined opposition. Mittag-Leffler persuaded Birkeland to come to Stockholm in May 1905 to discuss the position at the college with, among others, Arrhenius and Bjerknes, but in the end Birkeland decided not to apply for the position. There is little doubt that Arrhenius considered him competition and used his influence to avoid the Norwegian physicist as his successor.

In the 1920s several physicists within the Nobel Committee campaigned against meteorology in particular and geophysics in general. One of the victims was Bjerknes, whose many nominations - between 1923 and 1945 he was nominated 12 times - never led to a prize. As a result of the campaign, geophysics, meteorology and other branches of 
cosmical physics were de facto excluded from the Nobel Committee for Physics. The only Nobel laureate who can to some extent be considered a cosmical physicist was the Austrian physicist Victor Hess, who received the 1936 prize for his discovery of cosmic rays in the early 1910s.

\section{Conclusions}

Although today Arrhenius is primarily known for his important contributions to physical chemistry and to some extent also for his prediction of the greenhouse effect, his work ranged widely and included aspects of what would be later called geo- and space sciences. Less anachronistically, he worked within the diffuse context of what in the early 20th century was known as cosmical physics. His innovative theory of the aurora and comets' tails caused by solar radiation pressure attracted much attention at the time, and it was only one among many theories that flowed from his fertile mind.

By looking at Arrhenius' work in the period, one gets an impression of the content and scope of cosmical physics and why this umbrella discipline was highly regarded by many meteorologists and earth scientists. However, it never transformed into a normal scientific discipline and did not survive World War I. One reason was undoubtedly that scientists had widely different conceptions of what cosmical physics was or should be about, for example, of whether astronomy belonged to the field or not. Whereas some scientists considered meteorology and terrestrial magnetism to be the core fields of cosmical physics, others placed more emphasis on solar physics and astrophysics generally. Arrhenius' textbook of 1903 spanned over the entire spectrum, yet without providing a unified framework for the many subjects ranging from oceanography to cosmogony. As a further indication of the weakness of cosmical physics, there were no attempts to promote it by means of either a scientific journal or a research school.

The result was that cosmical physics remained a label rather than a real organizational unit for doing science. It eventually dissolved, soon to be forgotten. When the International Union for Geodesy and Geophysics (IUGG) was founded in 1919, it comprised six sections, namely, geodesy, meteorology, terrestrial magnetism and electricity, seismology, physical oceanography, and the study of volcanoes. Cosmical physics was not included, nor did it appear in other unions of the newly established International Research Council.

Edited by: S. Silverman

Reviewed by: A. Brekke and one anonymous referee

\section{References}

Amelin, O.: Physics as ideology: Svante Arrhenius as a writer of popular science, in: Center on the Periphery: Historical Aspects of 20th-Century Swedish Physics, 42-57, edited by: Lindqvist, S., Science History Publications, Canton, MA, 1993.

Arrhenius, G.: Svante Arrhenius' contribution to earth science and cosmology, in: Svante Arrhenius, till 100-Årsminnet av hans Födelse, 67-81, edited by: Arrhenius, O., Arrhenius-Wold, A.L., and Arrhenius, G., Almqvist \& Wiksell, Uppsala, 1959.

Arrhenius, G., Caldwell, K., and Wold, S.: A Tribute to the Memory of Svante Arrhenius, Royal Swedish Academy of Engineering Sciences, Stockholm, 2008.

Arrhenius, S.: Iakttagelser rörande klotblixt, Översikt Kungl. Svenska Vetenskapsakademins Förh., 7, 77-86, 1883.

Arrhenius, S.: Über das Leitungsvermögen der phosphorescirenden Luft, Ann. Phys. Chem., 32, 545-572, 1887.

Arrhenius, S.: Über den Einfluss der Sonnenstrahlung auf die elektrischen Erscheinungen in der Erdatmosphäre, Meteorol. Zeits., 5, 297-304, 348-360, 1888.

Arrhenius, S.: On the influence of carbonic acid in the air upon the temperature on the ground, Phil. Mag., 41, 237-276, 1896.

Arrhenius, S.: Über die Ursache der Nordlichter, Physik. Zeits., 2, 81-87, 97-105, 1900.

Arrhenius, S.: Zur Physik des Vulkanismus, Geol. Fören. Förhandl., 22, 26-36, 1901a.

Arrhenius, S.: Zur Kosmogonie, Arch. Néerl. Sci. Exact. Natur., 6, 862-873, 1901b.

Arrhenius, S.: On the electric equilibrium of the sun, Month. Not. Roy. Astron. Soc., 64, 496-499, 1903a.

Arrhenius, S.: Lehrbuch der kosmischen Physik, Hirzel, Leipzig, 1903 b.

Arrhenius, S.: Worlds in the Making: The Evolution of the Universe, Harper \& Brothers, New York, 1908.

Birkeland, K.: Sur les rayons cathodiques sous l'action de forces magnétiques intenses, Arch. Sci. Phys. Nat., 1, 497-512, 1896.

Birkeland, K.: Expédition Norvégienne de 1899-1900 pour l'etude des aurores boréales, Videnskabsselsk. Skr. I, Mat.-Nat. Klasse, no. 1, Oslo, 1901.

Brekke, A. and Egeland, A.: The Northern Light: From Mythology to Space Research, Springer-Verlag, Berlin, 1983.

Carazza, B. and Kragh, H.: Adolfo Bartoli and the problem of radiant heat, Ann. Sci., 46, 183-194, 1989.

Coffey, P.: Cathedrals of Science: The Personalities and Rivalries that Made Modern Chemistry, Oxford University Press, Oxford, 2008.

Cox, J.: Comets' tails, the corona and the aurora borealis, Pop. Sci. Month., 60, 266-278, 1902.

Crawford, E.: The Beginnings of the Nobel Institution: The Science Prizes, 1901-1915, Cambridge University Press, Cambridge, 1984.

Crawford, E.: Arrhenius: From Ionic Theory to the Greenhouse Effect, Science History Publications, Canton, MA, 1996.

Crawford, E.: Arrhenius' 1896 model of the greenhouse effect in context, Ambio, 26, 6-11, 1997.

Davis, W. H.: The International Congress of Arts and Science, Pop. Sci. Month., 66, 5-32, 1904.

Egeland, A. and Burke, W. J.: Kristian Birkeland: The First Space Scientist, Springer, Dordrecht, 2010. 
Fleming, J. R.: Historical Perspectives on Climate Change, Oxford University Press, Oxford, 1998.

Friedman, R. M.: The Politics of Excellence: Behind the Nobel Prize in Science, W. H. Freeman, New York, 2001.

Goldstein, E.: Ueber die Entladung der Elektricität in verdünnten Gasen, Ann. Phys., 12, 249-279, 1881.

Gooday, G.: Cosmos, climate and culture: Manchester meteorology made universal, Manchester Region Hist. Rev., 18, 63-83, 2007.

Halm, J.: On prof. Arrhenius' theory of cometary tails and auroræ, Nature, 65, 415-416; 66, 55-56, 1902.

Harvey, E. N.: A History of Luminescence: From the Earliest Times until 1900, American Philosophical Society, Philadelphia, 1957.

Hedenus, M.: Der Komet in der Entladungsröhre: Eugen Goldstein, Wilhelm Foerster und die Elektrizität im Weltraum, GNT-Verlag, Stuttgart, 2007.

Heidarzadeh, T.: A History of Physical Theories of Comets, from Aristotle to Whipple, Springer, New York, 2008.

Holmberg, P.: From dogmatic discussions to observations and planned experiments: Some examples from early aurora borealis research in Finland, Sci. Educ., 5, 267-276, 1996.

Jørgensen, T. S. and Rasmussen, O.: Adam Paulsen, a pioneer in auroral research, EOS, 87, 61-66, 2006.

Kragh, H.: The rise and fall of cosmical physics: Notes for a history, ca. 1850-1920, arxiv: 1304.3890, 2013.

Lebedev, P.: Les forces de Maxwell-Bartoli dues a la pression de la lumière, in: Rapports Présentés au Congrès International de Physique, Vol. 2, 133-140, edited by: Guillaume, C. E. and Poincaré, L., Gauthier-Villars, Paris, 1900.

Lebedev, P.: Untersuchungen über die Druckkräften des Lichtes, Ann. Phys., 6, 433-458, 1901.

Lockyer, W. J.: Text-book of cosmical physics, Nature, 50, 49-50, 1894.

Maxwell, J. C.: A Treatise on Electricity and Magnetism, Clarendon Press, Oxford, 1873.
Müller, J.: Lehrbuch der kosmischen Physik, Vieweg und Sohn, Braunschweig, 1856.

Müller, J. and Peters, C. F. W.: Joh. Müller's Lehrbuch der kosmischen Physik, Vieweg und Sohn, Braunschweig, 1894.

Paulsen, A.: Sur la nature et l'origine de l'aurore boréale, Bull. l'Acad. Roy. Sci. Danemark, 2, 148-168, 1894.

Paulsen, A.: Sur les récentes theories de l'aurore polaire, Bull. l'Acad. Roy. Sci. Danemark, 2, 109-144, 1906.

Pettersson, O.: Climatic variations in historic and prehistoric times, Svenska Hydrogr.-Biol. Komm. Skrifter, 5, 1-26, 1914.

Reynolds, O.: The tails of comets, the solar corona, and the aurora, considered as electrical phenomena, in: Papers on Mechanical and Physical Subjects, Vol. 1, 7-14, Cambridge University Press, Cambridge, 1900.

Riesenfeld, E. H.: Svante Arrhenius, Akademische Verlagsgesellschaft, Leipzig, 1931.

Schwarzschild, K.: Der Druck des Lichts auf kleine Kugeln und die Arrhenius'sche Theorie der Cometenschweife, in: Karl Schwarzschild: Gesammelte Werke, Vol. 1, 317-322, edited by: Voigt, H. H., Springer-Verlag, Berlin, 1992.

Stauning, P.: Danish auroral science history, Hist. Geo Space. Sci., 2, 1-28, doi:10.5194/hgss-2-1-2011, 2011.

Stewart, B.: The recent developments of cosmical physics, Nature, 2, 499-501, 1870.

Stubhaug, A.: Gösta Mittag-Leffler: A Man of Conviction, SpringerVerlag, Berlin, 2010.

Thomson, J. J.: The existence of bodies smaller than atoms, Proc. Roy. Inst., 16, 138-150, 1901.

Thomson, J. J.: Conduction of Electricity through Gases, Cambridge University Press, Cambridge, 1903.

Trabert, W.: Lehrbuch der kosmischen Physik, B. G. Teubner, Leipzig, 1911.

Ule, O.: Die Natur: Ihre Kräfte, Gesetze und Erscheinungen im Geiste kosmischer Anschauung, H. W. Schmidt, Halle, 1851. 